\title{
Rancang Bangun Penerapan Teknologi SMS Gateway Terintegrasi Mesin Biometrik pada Sistem Informasi Akademik
}

\author{
Eko Harli ${ }^{1}$, Ahmad Fauzi ${ }^{2}$ \\ 1,2 Informatika, Universitas Indraprasta PGRI \\ 1eko.harli@gmail.com \\ 3ahmad.fauzi@gmail.com
}

\begin{abstract}
Abstrak- Proses penyebaran informasi yang cepat menjadi sebuah keharusan pada masyarakat modern sekarang ini. Dalam dunia pendidikan penyebaran informasi dapat dilakukan dengan menggunakan teknologi SMS Gateway, salah satunya adalah SMK Negeri 1 Depok yang memanfaatkan teknologi SMSGateway pada Sistem Informasi Akademik, namun sistem yang berjalan masih kurang efektif untuk data absensi siswa, permasalahan tersebut dapat diselesaikan dengan menggunakan mesin biometric yang terintegerasi dengan sistem akademik, sehingga sistem akademik mendapatkan data yang realtime, untuk dapat diolah dan disebarluaskan melalui SMS informasi ketidak hadiran siswa. Penelitian ini menggunakan metode kualitatif dengan ditunjang metode pengembangan perangkat lunak Rapid Application Development dalam pembuatan sistem. Untuk integrasi data, penelitian ini menggunakan library opensource java yang bernama beanIO agar data yang didapat dari mesin biometric dapat diolah dengan mudah. Hasil akhir dari penelitian ini menunjukan bahwa dengan menggunakan mesin biometrik sidikjari pada proses absensi siswa dapat meminimalisir keslahan dan mempercepat proses penyebaran informasi ketidak hadiran siswa kepada orangtua.
\end{abstract}

Kata Kunci-Biometrik, SMS-Gateway, Akademik, Gammu.

\section{Pendahuluan}

Proses penyebaran informasi yang cepat menjadi sebuah keharusan pada kehidupan masyarakat modern sekarang ini, hal tersebut tidak terlepas dari teknologi informasi yang semakin berkembang dan seakan menolak untuk berhenti. Pesatnya perkembangan teknologi informasi dan komunikasi telah merambah berbagai bidang kehidupan tidak terkecuali bidang pendidikan dan pengajaran [1].

Dalam dunia pendidikan akibat terbesar dari perkembangan teknologi informasi dan komunikasi diantaranya adalah mulai banyaknya bermunculan e-learning (pembelajaran berbasis internet), kelas virtual, dan sistem informasi akademik dalam mengelola kegiatan akademik pada suatu instansi pendidikan. Penerapan teknologi informasi pada suatu instansi tidak lain untuk mempermudah kegiatan operasionalnya dengan harapan dapat menghasilkan informasi yang berkualitas, yaitu informasi yang akurat, relevan dan tepat waktu [2].

SMK Negeri 1 Depok sebagai salah satu instansi pendidikan yang sedang berkembang telah menerapkan teknologi informasi dalam menunjang kegiatan akademiknya. Sistem Informasi Akademik (SIAKAD) SMK Negeri 1 Depok telah menerapkan teknologi SMS Gateway untuk penyebar luasan informasi [3].
Short Message Service (SMS) adalah salah satu layanan teknologi informasi yang berbasis telepon seluler. SMS gateway adalah media penyebaran informasi berbasis SMS yang telah ada sejak lama, bahkan sempat dianggap merupakan teknologi lama yang mulai ditinggalkan. Akan tetapi saat ini SMS gateway sudah kembali digunakan oleh instansi-instansi sebagai salah satu alat pengelola informasi selain welalui website. SMS dianggap sebagai dua fungsi utama yang sering digunakan oleh masyarakat untuk berkomunikasi [2][4].

Secara umum SIAKAD yang ada digunakan untuk menyebarkan informasi kegiatan sekolah, mulai dari informasi pelaksanaan ujian, informasi nilai, informasi tanggal-tanggal penting kegiatan di sekolah, hingga informasi absensi siswa. Informasi tersebut disampaikan melalui media SMS, yang dapat dipicu oleh sistem maupun dengan fitur autoreply pada sistem yang dibangun.

Dalam kegiatan pengumpulan informasi absensi siswa, sistem yang berjalan sekarang ini masih belum maksimal, dikarenakan pengumpulan data masih melakukan proses manual disetiap kelas, kemudian memindahkannya kedalam sistem. Sehingga ada kalanya orangtua yang ingin mengetahui apakah anaknya datang ke sekolah atau tidak, informasi belum dapat diberikan karena rekap absensi harian belum selesai diolah.

Kekurangan dalam proses manual rekapitulasi absensi ini untuk menunjang sistem informasi akademik yang ada, dapat diselesaikan dengan penggunaan sebuah perangkat biometrik untuk mengidentifikasi kehadiran siswa secara real-time yang dapat diintegrasikan kedalam sistem informasi akademik yang ada.

Biometrik adalah teknologi khusus yang biasa digunakan pada medis untuk mengidentifikasi manusia dengan melihat atau mendeteksi karakteristik tertentu yang ada pada diri manusia itu sendiri. Adapun, karakteristik yang diidentifikasi menggunakan sistem biometrik ini bisa saja berupa sidik jari, bentuk wajah, mata, dan suara manusia [5].

Pada penelitian ini bagian biometrik yang digunakan yaitu sidik jari. Dengan demikian selain pengumpulan data absensi yang awalnya bersifat manual, dapat dilakukan secara otomatis dengan adanya mesin biometrik ini, selain itu keuntungan yang didapat adalah dalam proses absensi sekolah, siswa tidak bisa melakukan tindak kecurangan absensi seperti menitipkan absen kepada siswa lain, karena sidik jari antar siswa satu dengan yang lain pasti berbeda-beda. 
Tantangan dalam mengintegrasikan 2 atau lebih sistem yang berbeda kerap kali menjadi suatu permasalahan yang sulit dipecahakan [6]. Dalam mengintegrasikan mesin biometrik dengan sistem informasi akademik yang ada, penelitian ini menggunakan konsep formatting data menggunakan library beanIo, dimana library tersebut mampu untuk memanipulasi data yang akan dimasukan kedalam sistem dengan format yang disesuaikan antara pengirim data dengan penerima data.

Penelitian ini bertujuan untuk mengintegrasikan mesin biometerik dengan sistem informasi akademik yang telah ada pada SMK Negeri 1 Depok yang telah terintegrasi dengan teknologi SMS Gateway.

\section{KAJIAN PUSTAKA}

Bagian ini menyajikan teori-teori yang terkait dengan masalah penelitian yang terfokus pada teori mengenai perancangan sistem, integrasi mesin biometrik dan sms gateway. Juga menyajikan penelitian-penelitian yang berkaitan dengan penelitian ini.

\section{A. Penelitian yang Relevan}

Dengan semakin berkembangya teknologi informasi, telah banyak penelitian-penelitian sebelumnya yang relevan dengan penelitian ini.

Pada tahun 2014, Parlika dkk, melakukan penelitian mengenai sistem absensi sidik jari terintegarasi SMS Gateway berbasis desktop menggunakan visual basic dan MySQL, penelitian ini menghasilkan sebuah aplikasi sistem absensi sidik jari, dimana setalah dilakukan implementasi sistem diketahui bahwa pencatatan kehadiran dengan menggunakan sidik jari akan lebih valid karena sidik jari bersifat unik. Sidik jari seseorang tidak dapat digantikan oleh sidik jari orang lain. Selain itu dengan teknologi SMS Gateway, orang tua akan lebih mudah untuk memperoleh informasi kehadiran putra/putrinya [8].

Pada tahun 2015, Indriyawati melalukan analisis sistem informasi akademik berbasis SMS Gateway pada Fakultas Teknologi Informasi dan Komunikasi Universitas Semarang, penelitian ini hanya terfokus pada membahas bagaimana informasi mengenai nilai mahasiswa dapat disebarluaskan melalui fitur SMS Gateway[7].

Pada tahun 2017 Sihotang dan Jumailah melakukan pengembangan SMS Gateway terhadap layanan informasi Sistem Informasi Akademik di STMIK GI MDP, penelitian ini mengembangkan SMS Gateway sehingga informasi mengenai monitoring absensi, nilai matakuliah, IPK dan berita akademik dapat diakses melalui SMS, selain itu penelitian ini meningkatkan layanan informasi antara orangtua dengan kampus [2].

Pada tahun yang sama Fauzi dan Harli, melakukan penelitian pada perancangan sistem informasi akademik berbasis SMS Gateway menggunakan metode RAD. Penelitian ini menghasilkan sebuah sistem informasi akademik yang dapat mengirimkan informasi nilai dari fitur autoreply kepada orangtua, juga jadwal kegiatan akademik dan absensi putra/putrinya kepada orangtua [3].

Berdasarkan penelitian-penelitian sebelumnya, penelitian ini menitikberatakan pada bagaimana mengintegrasikan mesin biometrik sebagai alat pengumpulan data absensi kedalam sistem informasi akademik yang telah berajalan, sehingga proses pengiriman sms siswa yang tidak masuk berjalan secara terjadwal dan terotomatisasi.

\section{Metode Penelitian}

Metode penelitian yang digunakan pada penelitain ini dibagi kedalam 2 bentuk, dimana penelitian ini merupakan jenis penelitian deskriptif yaitu penelitian yang mengolah data bukan berupa angka melainkan berwujud kata-kata [9]. Sedangkan dalam pengembangan dan perancangan sistem, penelitian ini menggunakan metode Rapid Application Development (RAD). Rapid Application Development adalah proses model perangkat lunak yang berkembang sedikit demi sedikit secara teratur dimana proses modelnya menekankan siklus pengembangan yang singkat [10].

\section{A. Analisis Data}

Sumber data pada penelitian ini dibagi menjadi 2 sumber, yaitu data primer dan data sekunder. Untuk data primer, data didapat langsung dari mesin biometrik dan dari SMK Negeri 1 Depok dengan metode wawancara dalam pengumpulan data. Sedangkan untuk data sekunder didapat dari jurnal-jurnal dan buku-buku teoritis yang terkait.

Untuk menganalisis data mentah yang didapat pada proses pengumpulan data, digunakan teknik analisis data kualitatif. Dimana teknik ini terdiri dari 3 proses: 1) Reduksi Data, 2) Triangulasi Data, 3) Penarikan Kesimpulan

\section{B. Langkah-langkah Penelitian}

Penelitian ini dilakukan pada SMK Negeri 1 Depok, dengan langkah-langkah penelitian yang dilakukan merujuk pada metode perancangan Rapid Application Development [3]:

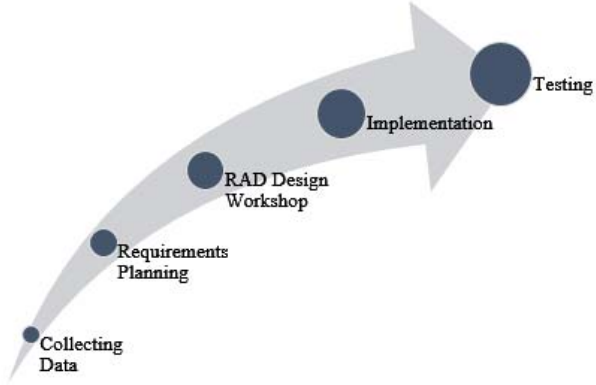

Gambar 1. Langkah-langkah Penelitian

Langkah awal pada penelitian ini merupakan tahapan pengumpulan data, data yang dikumpulkan kemudian diolah dengan menggunakan teknik analisis data kualitatif, data yang diolah adalah data hasil ekstraksi dari mesin biometrik yang akan diintegrasikan kedalam sistem informasi akademik yang 
ada. Data yang didapat berupa file txt yang berisi record siswa dalam melakukan absensi.

Langkah berikutnya setelah proses pengumpulan data adalah dengan melakukan tahapan Rapid Application Development yang terdiri dari Requirements Planning, RAD Design Workshop, Implementation.

Tahapan Requirements Planning merupakan tahapan perencanaan kebutuhan sistem, melibatkan pengguna untuk merancang dan membangun sistem, RAD Design Workshop merupakan tahapan menentukan arsitektur, rancangan layar, spesifikasi sistem. Implementation merupakan tahapan pengimplementasian seluruh kegiatan sebelumnya [11].

Tahapan terakhir merupakan pengujian sistem (testing) untuk memastikan seluruh kebutuhan sistem pada tahapan Requirement Planning dan Perancangan Sistem yang dilakukan sebelumnya berjalan dengan baik. Pengujian dilakukan dengan 2 metode, yaitu pengujian yang dilakukan menggunakan metode black box testing yaitu pengujian perangkat lunak tanpa melihat struktur kode program, melainkan hanya menilai dari fungsional fitur aplikasi [2]. Dan pengujian kualtias perangkat lunak berdasarkan standar ISO 9126.

\section{HASIL DAN PEMBAHASAN}

Dalam melakukan proses integrasi data dari mesin biometrik kedalam sistem informasi akademik, menggunakan libaray tambahan yang bernama beanIo, library ini merupakan opensource berbasis java yang dapat memudahkan pemetaan dari text file kedalam object untuk selanjutnya diolah pada sistem.

Untuk pengembangan sistem yang telah ada, metode Rapid Application Development tetap dilakukan melanjutkan hasil penelitian sebelumnya, dimana penelitian ini menerapakn langkah-langkah Rapid Application Development sebagai berikut:

\section{A. Requirements Planning}

Requirements planning adalah proses perencanaan yang berhubungan dengan kebutuhan sistem yang akan dibangun, proses ini juga sangat erat hubungannya dengan proses pengumpulan data, proses requirements dilakukan dengan metode diskusi, sehingga kebutuhan pengguna lebih jelas dan arah dari sistem lebih tertuju pada hasil yang diharapkan.

Tabel 1 memperlihatkan rincian dari kebutuhan-kebutuhan sistem, hasil dari requirements planning:

TABEL I

HASIL REQUIREMENT PLANING

\begin{tabular}{|c|l|}
\hline No & \multicolumn{1}{|c|}{ Kebutuhan Sistem } \\
\hline 1 & $\begin{array}{l}\text { Dapat mengirimkan informasi dalam jumlah banyak dan } \\
\text { bersamaan melalui sms }\end{array}$ \\
\hline 2 & Terdapat fitur auto replay untuk format sms tertentu \\
\hline 3 & Dapat dintegrasikan dengan mesin biometrik sidik jari \\
\hline 4 & $\begin{array}{l}\text { Data dari mesin biometrik otomatis masuk kedalam sistem } \\
\text { informasi akademik setiap harinya }\end{array}$ \\
\hline 5 & $\begin{array}{l}\text { Sistem akan otomatis mengirim pesan kepada orang tua } \\
\text { siswa jika ada anaknya yang tidak masuk sekolah }\end{array}$ \\
\hline
\end{tabular}

\section{B. RAD Design Workshop}

Hasil daripada proses RAD design workshop antara lain adalah: arsitektur sistem, rancangan tampilan layar dan spesifikasi pendukung perangkat lunak lainya.

Arsitektur dari sistem yang dibangun terdiri dari 4 layer utama, yaitu layer pengguna, layer teknologi sms, layer biometrik, dan layer aplikasi. Arsitektur ini merupakan pengembangan yang dilakukan terhadap design arsitektur penelitian sebelumnya, dengan menambahkan layer biometrik.

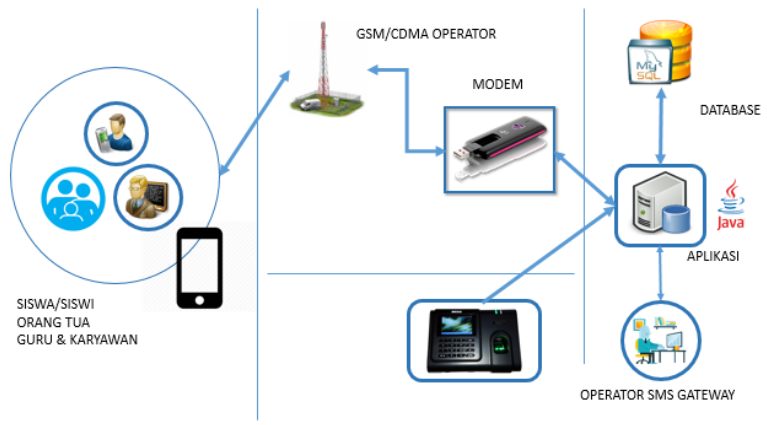

Gambar 2. Arsitektur Sistem

Layer pengguna berisi siswa, orangtua, guru/karyawan SMK Negeri 1 Depok yang akan mengirim atau menerima Informasi akademik dari sistem yang dibangun melalui media SMS.

Layer teknologi sms, layer ini berisi teknologi sms yang diatur menggunakan framework sms management sistem GAMMU, dengan perangkat penerima dan pengiriman sms dengan sebuah modem dan simcard.

Layer Biometrik, layer ini berisi teknologi biometrik untuk mengidentifikasi sidik jari siswa untuk melakukan absensi kehadiran. Data yang terdapat pada mesin biometrik akan otomatis dikirim ke sistem informasi akademik untuk diolah, sehingga akan mengirimkan sms jika ada siswa yang tidak melakukan absensi.

Layer terkahir berisi aplikasi sistem informasi akademik, dimana sistem ini terintegrasi dengan sistem manajemen sms (sms-gateway), sebagai sumber data untuk penyebaran informasi. Sistem ini dibangun dengan menggunakan bahasa pemrograman java dan untuk manajemen basis data menggunakan RDBMS MariaDB.

Dari arsitektur yang dibuat, kemudian menentukan rancangan layar untuk sistem yang dibangun. Khusus untuk tampilan visual (design user interface) penelitian ini berpatokan kepada 6 prinsip dasar perancangan user interface, yaitu:

- Layout, User Interface sebaiknya merupakan serangkaian area yang digunakan secara konsisten. 
- Context Awareness, User harus selalu sadar/mengetahui dengan sangat baik akan posisi mereka berada.

- Aesthetics, User interface harus fungisonal, selain itu juga sering kali ada trade-off antara termasuk ruang putih yang cukup untuk membuat tampilan antarmuka menyenangkan

- User Experience, memiliki kemudahan untuk dipelajari

- Consistency, Konsistensi dalam desain antarmuka memungkinkan pengguna untuk memprediksi apa yang akan terjadi sebelum mereka melakukan fungsi.

- Minimal User Effort, Antarmuka harus sederhana untuk digunakan.

Berikut adalah beberapa rancangan layar yang digunakan pada sistem informasi akademik untuk sisi sms-gateway.
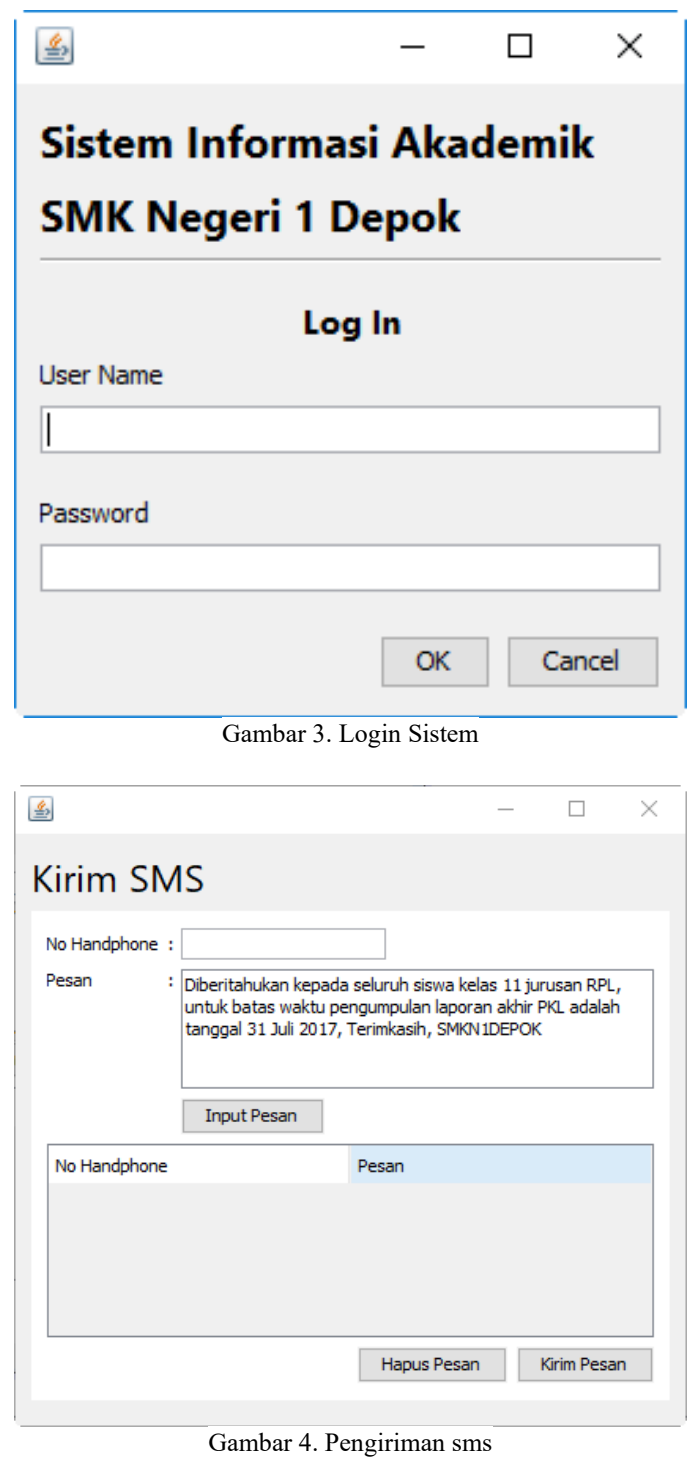

\section{Implementation}

Implementation dari dua tahap sebelumnya dilakukan dengan mulai membangun sistem dari hasil rancangan dan kebutuhan-kebutuhan sistem. Dari tahapan-tahapan sebelumnya didapat bahwa untuk mengimplementasikan rancangan yang dibuat dibutuhkan beberapa hal yaitu:

- Server yang digunakan adalah Apache Web Server

- Sistem manajemen Basis data menggunakan MariaDB

- Sistem Informasi akademik berbasis sms gateway dibangun menggunakan bahasa pemrograman JAVA.

- Penghubung antara sistem informasi dengan pihak eksternal yaitu media informasi SMS, dengan menggunakan framework Gammu.

- Penghubung antara mesin biometric dengan system informasi akademik adalah sebuah jaringan local yang tersambung dengan LAN, dan terdapat scheduler yang akan mengambil data absensi setiap jam 9 pagi setiap harinya.

\section{Testing}

Pengujian sistem yang dibangun menggunakan metode pengujian blackbox, dimana semua kebutuhan utama dalam sistem diuji secara fungsionalitasnya, berikut hasil pengujian blackbox disajikan pada tabel II:

TABEL III

HASIL PENGUJIAN SISTEM

\begin{tabular}{|l|c|}
\hline Komponen Pengujian & Hasil \\
\hline Mengirim banyak sms sekaligus & OK \\
\hline Menerima sms & OK \\
\hline Fitur Auto replay dengan format tertentu & OK \\
\hline $\begin{array}{l}\text { Mengirimkan kesalahan format pengiriman } \\
\text { sms }\end{array}$ & OK \\
\hline $\begin{array}{l}\text { Menampilkan pesan yang diterima dalam } \\
\text { bentuk laporan }\end{array}$ & OK \\
\hline Manajemen data untuk seluruh kontak & OK \\
\hline $\begin{array}{l}\text { Otomatisasi pengambilan data dari mesin } \\
\text { biometrik secara berkala }\end{array}$ & OK \\
\hline $\begin{array}{l}\text { Mengirimkan SMS ketidakhadiran siswa } \\
\text { kepada orang tua secara otomatis berdasarkan } \\
\text { data dari mesin biometrik }\end{array}$ & \\
\hline
\end{tabular}

\section{KESIMPULAN}

Metode Rapid Application Development dalam membangun sistem informasi berbasis teknologi sms-gateway secara nyata dapat memberikan hasil yang lebih cepat dan efisien. Seluruh kebutuhan sistem terpenuhi dari tahap requirements planning. Tahapan RAD design memberikan fleksibelitas pada saat merancang, karena tidak terpaku hanya pada sebuah proses saja. Implementasi jadi lebih cepat karena kebutuhan pengguna yang sudah jelas. Selain itu penggunaan library beanIo dalam integrasi data antara mesin biometrik dengan sistem informasi akademik menjadi lebih mudah. Hasil pengujian blackbox memperlihatkan bahwa sistem yang dibangun sesuai dengan kebutuhan fungsionalitas yang diperlukan SMK Negeri 1 Depok terutama integrasi dengan mesin biometrik dalam proses absensi. 


\section{REFERENSI}

[1] A. Ibrahim, "Pengembangan Sistem Informasi Monitoring Tugas Akhir Berbasis Short Message Service (SMS) Gateway di Fasilkom Unsri," Jusi, vol. 1, no. 2, pp. 81-92, 2011.

[2] SIHOTANG, Fransiska Prihatini; JUMEILAH, Fithri Selva. Pengembangan SMS Gateway Layanan Informasi Akademik di STMIK GI MDP. Jurnal RESTI (Rekayasa Sistem dan Teknologi Informasi), [S.1.], v. 1, n. 1, p. 58 - 63, aug. 2017. ISSN 2580-0760 Available at: $<$ http://jurnal.iaii.or.id/index.php/RESTI/article/view/12>

[3] FAUZI, Ahmad; HARLI, Eko. Rancang Bangun Sistem Informasi Akademik Berbasis SMS Gateway dengan Metode Rapid Application Development. URECOL, [S.1.], sep. 2017. Available at: $<$ http://journal.ummgl.ac.id/index.php/urecol/article/view/1491>.

[4] Persada, Satria, at all. (2013). Toward Paperless Public Announcement on Environmental Impact Assessment (EIA) through SMS Gateway in Indonesia. International Conference on Sustainable Future for Human Security4th pp 271-279.

[5] Gat, "Integrasi Fingerprint System Dengan Real Time Absensi Dosen Berbasis Web ( Studi Kasus : STMIK Pontianak )," Cogito Smart J., vol. 2, no. 2, pp. 135-146, 2016.

[6] Sutanta, E., \& Ashari, A., 2012, Distribusi Basis Data Kependudukan untuk Optimalisasi Akses Data: Suatu Kajian Pustaka, Jurnal Ilmu Komputer, no 5, vol 1, hal 1-9.

[7] H. Indriyawati, "ANALISIS SISTEM INFORMASI AKADEMIK BERBASIS SMS GATEWAY PADA FAKULTAS TEKNOLOGI INFORMASI DAN KOMUNIKASI UNIVERSITAS SEMARANG," Jurnal. Transformatika., vol. 13, no. 1, pp. 8-12, 2015.

[8] Parlika, Rizky, Et al (2014), Sistem Absensi Sidik Jari Terintegrasi SMS Gateway Berbasis Desktop Menggunakan Visual Basic dan Mysql, dari world wide web: http://eprints.upnjatim.ac.id/6415/1/Vo19No2Juni2014_-

Paper 2 Rizky Parlika dkk.pdf.

[9] Moleong, Lexy J. 2000. Metodologi Penelitian Kualitatif. Bandung: PT.Remaja Rosdakarya.

[10] Pressman, Roger S. 2012. Software Engineering: a practitioner's approach, 7th Edittion. New Work: Mcgraw-Hill.

[11] Kosasi S. Penerapan Rapid Application Development Dalam Sistem Perniagaan Elektronik Furniture. Citec J. 2015;2(4):265-76. 